\title{
Interleukin-3 Induces Hepatocyte-Specific Metabolic Activity in Bone Marrow-Derived Liver Stem Cells
}

\author{
Daniel Inderbitzin, M.D., Itzhak Avital, M.D., Adrian Keogh, Ph.D., Guido Beldi, M.D., \\ Mattia Quarta, M.D., Beat Gloor, M.D., Daniel Candinas, M.D.
}

\begin{abstract}
Bone marrow-derived adult liver stem cells (BALSC) are a promising target for the development of future cell-based therapies for a variety of liver disorders. However, the ability of stem cells to fully function, as hepatocytes, is limited and differentiation is time dependent. Therefore, it will be conducive to find a growth factor that is able to enhance liver-specific metabolic activity in freshly isolated liver stem cells. Recently, a subpopulation of BALSC was isolated and characterized ( $\beta 2$-microglobulin-negative/ Thy1-positive cells). We hypothesized that using interleukin-3 (IL-3), a hematopoietic differentiation growth factor, we may be able to enhance liver-specific metabolic activity in freshly isolated BALSC. Rat BALSC from normal and injured livers (bile duct ligated) were isolated and stimulated with IL-3 in culture. Cells were co-cultured with or without hepatocytes, separated by a semipermeable membrane. We measured the effect of IL-3 on BALSC to metabolize ammonia into urea (a liver-specific metabolic activity). IL-3 increased the ability of BALSC, purified from normal animals, to metabolize ammonia into urea by several folds. Interestingly, no such effect was found in cell cultures from bile ductligated animals. Additionally, co-cultures of BALSC with hepatocytes induced higher rate of ammonia metabolism, which was further enhanced by IL-3. Our study indicates that IL-3 may be used as an agent to enhance differentiation of BALSC, both qualitatively and quantitatively. It is conceivable that stem cells may undergo IL-3 priming before their clinical application in cell transplantation or bioartificial liver systems. (J Gastrointest Surg 2005;9:69-74) $\quad$ C 2005 The Society for Surgery of the Alimentary Tract
\end{abstract}

KEY WORDS: Hepatic stem cells, cytokine, metabolism, in vitro study, rodent

Ever since the first reports that a liver-specific stem cell can be isolated from the bone marrow of adult animals and humans, the clinical community has been enthralled by the potential promise of stem cell-based therapies for the treatment of the failing liver. ${ }^{1-9}$

Recently, we purified a heterogeneous population of progenitor cells that differentiated both in vivo and in vitro into hepatocytes. ${ }^{7,8} \mathrm{We}$ sorted bone marrow cells by means of MHC surface proteins and found that various subpopulations expressed several stem cell markers. ${ }^{7}$ Consequently, using magnetic beads, we developed a two-step immunoisolation procedure, further purifying cells expressing hepatocytespecific markers. These $\beta 2$-microglobulin-negative/ Thy-1-positive cells or bone marrow-derived adult liver stem cells (BALSC) were capable of multilineage differentiation, metabolizing ammonia into urea, and producing albumin and $\alpha$-fetoprotein (AFP). ${ }^{7}$ Furthermore, BALSC were able to repopulate and repair injured livers. ${ }^{8}$

However, one caveat is the need of these cells to be co-cultured with injured hepatocytes, separated by a semipermeable membrane, to maximally function, possibly due to yet unknown growth factor secreted by the hepatocytes in an attempt to recruit stem cells from the bone marrow. ${ }^{7}$

Interleukin-3 (IL-3) has a unique ability to stimulate the growth and differentiation of hematopoietic stem cells. ${ }^{10-13}$ However, its effect on BALSC is not known. ${ }^{14-19}$ Therefore, this study was undertaken to systematically evaluate the effect of IL-3 on BALSC.

We report here on the effects of IL-3 on liver stem cells in culture, with and without co-culture

Presented at the Forty-Fifth Annual Meeting of The Society for Surgery of the Alimentary Tract, New Orleans, Louisiana, May 15-19, 2004 (poster presentation).

From the Department of Visceral and Transplant Surgery (D.I., A.K., G.B., M.Q., B.G., D.C.), University Hospital Bern, Bern, Switzerland; and the Department of Surgery (I.A.), Memorial Sloan-Kettering Cancer Center, New York, New York.

Reprint requests: Daniel Inderbitzin, M.D., Department of Visceral and Transplant Surgery, University Hospital Bern, CH-3010 Bern, Switzerland. e-mail: daniel.inderbitzin@insel.ch 
with normal or injured hepatocytes (isolated from common bile duct-ligated animals). This study demonstrates that IL-3 might be used to stimulate more efficient function in freshly isolated BALSC, to render them competent to be used in cell transplantation therapies or bioartificial systems.

\section{MATERIAL AND METHODS}

All animal experiments were approved by the local committee for animal welfare in accordance with the European Convention on Animal Care. Male Sprague-Dawley rats (220-250 g; RCC Ltd., Füllinsdorf, Switzerland) were used in all experiments. There were eight experimental groups. In the first four (A-D), we isolated BALSC from the bone marrow of normal animals, and in the remaining four $(\mathrm{E}-\mathrm{H})$, the BALSC were derived from the bone marrow of rats after 7 days of bile duct ligation. We further divided groups A-D and E-H into cultures with $(\mathrm{C}, \mathrm{D}, \mathrm{G}$, and $\mathrm{H})$ and without $(\mathrm{A}, \mathrm{B}, \mathrm{E}$, and F) IL-3 and/or co-culture (A, C, E, and G) with syngeneic hepatocytes (Table 1).

\section{Culture Media}

Small hepatocyte culture media were prepared as described previously $y^{7,20}$ and supplemented with $5 \%$ heat-inactivated fetal calf serum (FCS; Invitrogen, Basel, Switzerland). The following growth factors were added to the cultures: hepatocyte growth factor (25 ng/ml; R\&D Systems, Minneapolis, MN), epidermal growth factor $(10 \mathrm{ng} / \mathrm{ml}$; Biosource, Camarillo, CA), and IL-3 (groups C, D, G, and H; IL-3, 10 ng/ml; R\&D Systems).

\section{Serum Harvest}

Whole rat blood was spun for 10 minutes at $1000 \mathrm{~g}$, and $1 \mathrm{ml}$ of sterile filtered serum $(5 \%, \mathrm{v} / \mathrm{v})$ was added to $19 \mathrm{ml}$ of culture media.

\section{Hepatocyte Isolation}

Hepatocytes from normal animals were isolated by a two-step portal collagenase perfusion of the liver as described previously by Berry and Friend. ${ }^{21}$ In 7-day bile duct-ligated animals, a retrograde perfusion was performed through the inferior vena cava.

For co-culture experiments, freshly isolated hepatocytes were seeded at a density of $150,000 \mathrm{cells} / \mathrm{cm}^{2}$ onto a collagen-coated $0.4-\mu \mathrm{m}, 6.5-\mathrm{mm}$ TranswellCOL-Inlay (Corning Costar Corporation, Bodenheim, Germany), and the hepatocyte culture transferred to an incubator with $5 \%(\mathrm{v} / \mathrm{v})$ of $\mathrm{CO}_{2}$ atmosphere at $37^{\circ} \mathrm{C}$.

\section{Harvesting of Bone Marrow Cells, Isolation and Culture of $\beta 2-M i c r o g l o b u l i n-N e g a t i v e$, Thy-1-Positive Cells}

We isolated BALSC from bone marrow as described recently by Avital and Inderbitzin. ${ }^{7}$ Freshly isolated $\beta 2$-microglobulin-negative/Thy-1-positive cells were then seeded at a density of 50,000 cells $/ \mathrm{cm}^{2}$ onto Matrigel-coated $\left(25 \mu \mathrm{g} / \mathrm{cm}^{2}\right.$; Becton Dickinson, Bedford, MA), 24-well cell culture plates (Corning Costar Corporation, Bodenheim, Germany). In the co-culture groups, the COL-Inlay with attached hepatocytes was inserted after 30 minutes, allowing the BALSC to achieve full attachment to the Matrigel layer. Single cultures and co-cultures were maintained in $500 \mu \mathrm{l}$ of media, changed every 3 days.

\section{Immunohistochemistry}

Freshly isolated BALSC ( $\beta 2$-microglobulin-negative/Thy-1-positive cells) were cyto-spun on glass slides, and the Universal Elite ABC Kit (PK-7200; Vector Lab Inc., Burlingame, CA) was used to stain for IL-3 receptor- $\alpha$ according to the manufacturer's guidelines (sc-681; Santa Cruz Biotechnology, Santa Cruz, CA).

\section{Determination of Urea Synthesis}

At 3, 6, 9, and 12 days of culture, the hepatocyte inlay was removed from the co-culture groups and

Table 1. Experimental groups

\begin{tabular}{lcccccc}
\hline & \multicolumn{2}{c}{ Normal rat } & & \multicolumn{2}{c}{ Bile duct-ligated rat } \\
\cline { 1 - 2 } Group & Coculture with hepatocyes & Interleukin-3 & & Group & Coculture with hepatocyes & Interleukin-3 \\
\hline A & Yes & No & & E & Yes & No \\
B & No & No & & F & No & Yes \\
C & Yes & Yes & & Y & Yes & Yes \\
D & No & Yes & H & No & \\
\hline
\end{tabular}

B2-Microglobulin-negative, Thy-1-positive bone marrow cells from normal (A-D) and bile duct-ligated rats (E-H) were cultured alone (B, $\mathrm{D}, \mathrm{F}$, and $\mathrm{H})$ or in coculture with isogeneic hepatocytes (A, C, E, and G), with (C, D, G, and H) or without interleukin-3 (A, B, E, and F). 
the culture media aspirated carefully. Then, $500 \mu \mathrm{l}$ of ammonia in Dulbecco's modified Eagle's medium (Sigma A 4514, 2.5 mmol/L, pH 7.40; Sigma Chemical, St. Louis, MO) was added to the BALSC cell cultures. After 5 hours, $400 \mu \mathrm{l}$ of media were removed, and ammonia and urea contents were determined using an enzymatic colorimetric test kit (Kit 542 946; Roche Diagnostics, Rotkreuz, Switzerland).

\section{Real-time Polymerase Chain Reaction}

Total RNA Extraction and Reverse Transcription. BALSC were harvested from culture using $500 \mu \mathrm{l}$ of TRIzol after complete removal of the media and immediately after determination of urea formation (Invitrogen AG). Total RNA was extracted using the Promega Reverse Transcription System (Promega Corporation, Madison, WI).

\section{Expression of Albumin mRNA and 18S rRNA Content}

The content of $18 \mathrm{~S}$ rRNA in each individual culture dish was quantified by TaqMan real-time polymerase chain reaction (PCR) (AB Applied Biosystems, Rotkreuz, Switzerland). Average threshold cycle values (cycle of threshold values) from triplicate real-time PCRs were obtained. Standardization of the metabolic signal for total cell number was achieved with the following formula: (Urea formation $/ \mathrm{h}) /\left(35\right.$ - CT value of $18 \mathrm{~S}$ rRNA). ${ }^{22}$

Albumin mRNA expression by BALSC was quantified by real-time PCR using the following primers and probe: forward primer: $5^{\prime}$-TTG GTG CAG GAA GTA ACA GAC TTT-3'; reverse primer: 5'GTG TGA ATG GAC TTG TCA CAG TTT T3'; and TaqMan probe: 5'-FAM-CAA AAT CAT GTG TCG CTG ATG AGA ATG CC-TAMRA-3' . Albumin $\triangle \mathrm{CT}$ values were related to $18 \mathrm{~S} \mathrm{rRNA}$ content in the following manner $(\Delta \mathrm{CT}$ albumin $=$ CT albumin - CT 18S rRNA).

\section{Interleukin-3 Determination in Serum}

IL-3 was measured using a colorimetric ELISA kit (900-K48; PeproTech EC Ltd., London, UK).

\section{Statistical Analysis}

Results are expressed as mean \pm SD. We compared parallel cultures from the same animal using a paired $t$ test. Intergroup comparisons were made using the Student $t$ test for normally distributed data. For correction of pairwise multiple comparisons, Student-Newman-Keuls method was applied (Jandel Scientific 1.0; Jandel Scientific, San Rafael, CA). The significance level was set at $\mathrm{P}<0.05$.

\section{RESULTS}

\section{Interleukin-3 Receptor- $\alpha$ Surface Expression}

Immunohistochemistry staining for IL-3 receptor$\alpha$ on BALSC from normal $(\mathrm{n}=3)$ and bile ductligated $(n=3)$ animals revealed that BALSC highly express IL-3 receptor- $\alpha$ : $95 \pm 5.0 \%$ in normal animals and $98 \pm 2.5 \%$ in bile duct-ligated animals $(P=0.70)$.

\section{Isolation of BALSC ( $\beta 2$-Microglobulin- Negative, Thy-1-Positive Cells) from Normal and Bile Duct-ligated Rats}

All rats survived 7 days of bile duct ligation. Body weight remained stable, and no signs of biliary or abdominal infection were observed. The subpopulation of $\beta 2$-microglobulin-negative cells was increased $(400 \%)$ in bile duct-ligated animals $(9.1 \pm 6.8 \%$ of all nucleated cells of the bone marrow in normal $[\mathrm{n}=28]$ versus $37.1 \pm 6.1 \%$ in bile duct-ligated animals [n $=12$ ], $P<0.0001)$. To obtain a pure fraction of albumin-positive cells, a Thy-1-positive selection was performed. ${ }^{7}$ Interestingly, no significant difference in the total cell number obtained after the second immunoisolation step was detected between cells isolated from normal and bile duct-ligated animals $(2.7 \pm 2.0 \%$ of all nucleated bone marrow cells in normal versus $3.4 \pm 1.0 \%$ in bile duct-ligated animals, $P=0.25)$.

\section{Real-time PCR for Albumin}

Albumin mRNA expression was assessed systematically in all BALSC used for culture experiments. $\triangle \mathrm{CT}$ values for albumin mRNA in $\beta 2$-microglobulin-negative/Thy-1-positive cells from normal $(19.9 \pm 2.4)$ and bile duct-ligated animals (21.4 \pm 4.1) were not different.

\section{Real-time PCR Analysis of 18S rRNA Content}

The determination of $18 \mathrm{~S}$ rRNA content in every single culture dish by real-time PCR showed stable CT values on culture days 3, 6, 9, and 12 (Table 2). Although the average standard deviation of the CT $18 \mathrm{~S}$ rRNA content in the groups E, F, G, and H (cells from bile duct-ligated animals) was higher than that in groups $\mathrm{A}, \mathrm{B}, \mathrm{C}$, and $\mathrm{D}$ (cells from normal animals), the statistical analysis revealed no significant differences among the eight experimental groups (Table 2).

\section{Ureagenesis}

Urea synthesis from ammonia was determined in BALSC on days 3, 6, 9, and 12 after removal of the hepatocyte inlay from the co-culture (Table 3). 
Table 2. 18S rRNA content of experimental groups

\begin{tabular}{lc}
\hline Experimental group & $\begin{array}{c}\text { Average 18S rRNA } \\
\text { content (CT values } \pm \text { SD) }\end{array}$ \\
\hline A & $24.5 \pm 1.2$ \\
B & $25.0 \pm 0.8$ \\
C & $26.6 \pm 1.4$ \\
D & $25.8 \pm 1.3$ \\
E & $26.0 \pm 4.0$ \\
F & $21.3 \pm 2.6$ \\
G & $21.4 \pm 3.9$ \\
H & $21.4 \pm 2.0$ \\
\hline
\end{tabular}

Total 18S rRNA content of the bone marrow-derived adult liver stem cells was determined at 3, 6, 9, and 12 days in culture and did not differ significantly over time under the various culture conditions examined, indicating constant cell number in all eight experimental groups.

Addition of IL-3 to the culture media increased the capacity of $\beta 2$-microglobulin-negative/Thy-1positive cells for urea formation in cell cultures from normal (A versus $\mathrm{C}, \mathrm{B}$ versus $\mathrm{D} ; P<0.05$ ) but not from bile duct-ligated animals ( $\mathrm{E}$ versus $\mathrm{G}, \mathrm{F}$ versus $\mathrm{H} ; P=\mathrm{NS}$ ) (Fig. 1).

As BALSC in single culture (B, D, F, and $\mathrm{H})$ and co-culture (A, C, E, and G) were strictly isolated from the same animal and kept in parallel cultures, a paired statistical analysis was performed (A versus B, C versus $\mathrm{D}, \mathrm{E}$ versus $\mathrm{F}, \mathrm{G}$ versus $\mathrm{H})$. All co-culture groups showed superior urea formation $(P<0.05)$.

When comparing urea formation capacity of BALSC from normal and bile duct-ligated donor animals under the same culture conditions (groups A versus $E, B$ versus $F, C$ versus $G, D$ versus $H$ ), no

Table 3. Metabolism of ammonia into urea in bone marrow-derived adult liver stem cells (BALSC)

\begin{tabular}{lcccc}
\hline & \multicolumn{5}{c}{$\begin{array}{c}\text { Urea synthesis } \\
\text { Experimental } \\
\text { Eroup }\end{array}$} & 3 Days & 6 Days & 9 Days & 12 Days \\
\cline { 2 - 5 } (average \pm SD) in BALSC cultures \\
\hline $\mathrm{A}$ & $1.3 \pm 0.2$ & $1.0 \pm 0.3$ & $1.9 \pm 0.1$ & $1.4 \pm 0.4$ \\
$\mathrm{~B}$ & $1.3 \pm 0.4$ & $0.5 \pm 0.1$ & $1.4 \pm 0.2$ & $0.8 \pm 0.1$ \\
$\mathrm{C}$ & $2.2 \pm 1.2$ & $2.1 \pm 0.9$ & $3.0 \pm 0.7$ & $3.4 \pm 1.5$ \\
$\mathrm{D}$ & $1.4 \pm 0.6$ & $1.8 \pm 1.3$ & $1.6 \pm 0.2$ & $2.0 \pm 0.3$ \\
$\mathrm{E}$ & $1.2 \pm 0.8$ & $2.0 \pm 0.4$ & $3.3 \pm 2.7$ & $3.1 \pm 0.1$ \\
$\mathrm{~F}$ & $1.1 \pm 1.0$ & $1.1 \pm 0.4$ & $2.7 \pm 2.2$ & $1.5 \pm 1.1$ \\
$\mathrm{G}$ & $2.3 \pm 0.7$ & $2.9 \pm 0.6$ & $3.9 \pm 0.6$ & $3.7 \pm 0.2$ \\
$\mathrm{H}$ & $2.0 \pm 0.1$ & $2.0 \pm 0.1$ & $2.9 \pm 0.1$ & $2.9 \pm 0.2$ \\
\hline $\mathrm{U}$ & & &
\end{tabular}

Urea synthesis was significantly increased $(P<0.05)$ in BALSC from normal animals after addition of interleukin-3 (groups $C$ and D) but unaltered in BALSC from bile duct-ligated animals (groups $\mathrm{G}$ and $\mathrm{H}$ ). All coculture groups (groups A, C, E, and G) showed superior ureagenesis compared with single BALSC cultures $(P<0.05)$. No significant differences were detected when comparing cell cultures from normal animals with parallel cultures from bile duct-ligated rats (groups A versus E; B versus F; C versus G; D versus H). significant differences were detected between the groups.

\section{Interleukin-3 Levels in Serum}

IL-3 levels in serum were determined in normal $(\mathrm{n}=3$, day 0$)$, sham-operated $(\mathrm{n}=3$, day 7$)$, and bile duct-ligated animals $(\mathrm{n}=3$, day 7$)$. Values were below the detection limit of the ELISA Kit used $(<0 \mathrm{ng} / \mathrm{ml})$.

\section{DISCUSSION}

The effect of IL-3 on proliferation and differentiation in early hematopoietic progenitor populations is well recognized. ${ }^{10-13}$ However, its effect on other progenitor cell populations like liver stem cells is not known. Using immunohistochemistry on freshly isolated BALSC revealed IL-3 receptor- $\alpha$ surface expression on virtually all $\beta 2$-microglobulin-negative/ Thy-1-positive cells isolated from rat bone marrow. This directed us toward the hypothesis that IL-3 may have a differentiation effect on BALSC. To test this hypothesis, we added IL-3 to cell cultures from normal animals (group D), which resulted in significantly stronger urea formation. This effect elicited a certain degree of excitement because it may provide a way to circumvent one of the most crucial problems in stem cell use for cell therapies. There are two cardinal problems for clinical application of stem cells: to obtain sufficient quantities ready for cell transplantation and to render these cells functional as soon as possible. Our study demonstrated that inducing hepatocyte-specific metabolic activity in BALSC within days of culture is feasible.

Previously, it has been established that to render BALSC functional in vitro, a co-culture with injured isogeneic hepatocytes separated by a semipermeable membrane is mandatory. ${ }^{7}$ Therefore, we compared the effect of IL-3 (groups C and D) on ureagenesis in cultures and co-cultures of BALSC from normal animals (groups A and B) to the potentially additional inductive effect of co-culturing injured hepatocytes from bile duct-ligated animals with BALSC (groups $\mathrm{E}$ and $\mathrm{G}$ ). Although ammonia metabolism into urea was impressively increased after stimulation with IL-3 in BALSC cultures from normal animals (groups A versus $\mathrm{C}$, B versus $\mathrm{D} ; P<0.05$ ), the metabolic signal was unaltered in BALSC co-cultures with hepatocytes from bile duct-ligated rats (groups A versus $\mathrm{E}, \mathrm{C}$ versus $\mathrm{G} ; P=\mathrm{NS}$ ). Furthermore, no $\mathrm{IL}-3$ was found in the serum of normal, sham-operated, or bile duct-ligated animals, which indicates that the induction of metabolic activity is highly specific for IL-3. 


\section{Urea synthesis in cultures of Beta-2-Microglobulin negative, Thy-1 positive bone marrow cells}

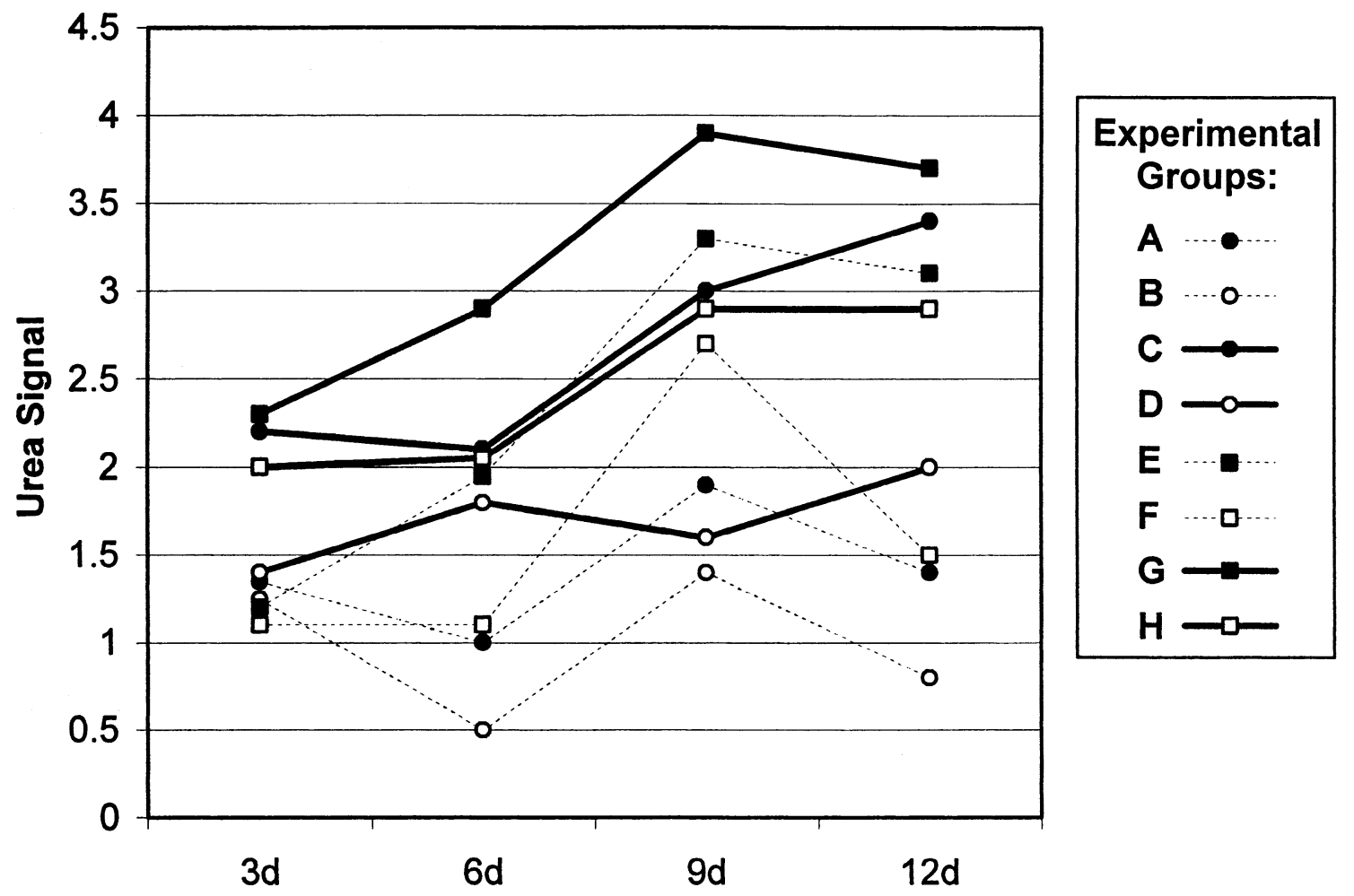

Days in Culture

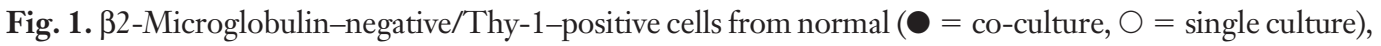
and bile duct-ligated ( $\square=$ co-culture, $\square=$ single culture) male rats were cultured in the presence (-) or absence (...) of interleukin-3 (IL-3). Urea synthesis from ammonia was determined on days 3, 6, 9, and 12 and standardized for cell number. Average urea formation is depicted and was strongest in group G. By addition of IL-3 to co-cultures of BALSC with hepatocytes from normal animals (group C), strong ureagenesis was inducible.

To further ascertain this phenomenon and to control for different cell numbers in the various cultures; we demonstrated that IL-3 did not promote cell expansion as $18 \mathrm{~S}$ rRNA content was stable in all eight culture conditions examined. This indicates a broader biological spectrum for the multilineage hematopoietic growth factor IL-3 than previously recognized. ${ }^{10-13}$

In culture experiments without tissue (liver) integration, mRNA or protein expression alone is not considered a reliable marker for the identification of organ-specific stem cells. ${ }^{6} \mathrm{We}$ therefore determined the urea formation capacity of $\beta 2$-microglobulinnegative/Thy-1-positive bone marrow cells under the culture conditions examined. The applied method of ammonia determination before and after urease addition to the sample allows internal control of total ammonia content. No background urea or ammonia was detected in the culture media sample alone. Standardization of urea formation was achieved by relation of the metabolic signal to individual $18 \mathrm{~S}$ rRNA content of the respective culture dish. This sensitive method allows quantitative assessment of urea formation in low-density cell cultures.

From a clinical point of view, the constant cell number in culture and the sustained urea formation of group D are most important. Human adult progenitor cell populations are readily accessible from the bone marrow, the peripheral blood after granulocyte colony-stimulating factor activation, and the umbilical cord blood. However, it is a difficult task to develop a hormonally defined culture medium that propagates unlimited liver progenitor cell division and liver-specific differentiation on demand. Interesting reports from various groups ${ }^{14-19}$ include different progenitor cell isolation procedures from the bone marrow and a variety of culture conditions used. Due to the different end points chosen (e.g., mRNA or protein expression of liver-specific genes like albumin), a comparison of the results obtained is not 
feasible and the effect of single additives (e.g., hepatocyte growth factor, acetic fibroblast growth, leucocyte migration inhibition factor) to the culture media remains unclear at best. Therefore, the hepatocytespecific metabolic capacity such as the urea production should be included in future in vitro studies of hepatic progenitor cell populations to obtain comparable results.

All co-cultures showed stronger ureagenesis than their corresponding parallel single cultures, and it is a formidable task to determine the factors responsible for this phenomenon. The BALSC cell pool, the serum added to the culture media, and the dynamic interplay between hepatocytes and BALSC during co-culture will have to be carefully elucidated in the future.

Based on the urea formation data obtained from co-cultures, we conclude that hepatocytes exert a direct inductive effect on $\beta 2$-microglobulin-negative/Thy-1-positive cells in culture. In a comparable in vitro study, Okumoto et al. ${ }^{16}$ showed a similar induction of albumin expression in co-cultures of a subpopulation of adult rat bone marrow cells with hepatocytes. As the bone marrow and liver cells in the described co-culture system are separated by a $0.4-\mu \mathrm{m}$ membrane, direct cell-to-cell interaction is precluded and paracrine soluble factors must be responsible for the induction of hepatocyte-specific function. Cell fusion between hepatocytes and progenitor cells as described as a potentially important in vivo mechanism is physically excluded in the twochamber co-culture experiments. ${ }^{23,24}$

\section{CONCLUSIONS}

Ethical and immunologic considerations indicate that adult bone marrow-derived liver stem cells may be superior to embryonic stem cells. The ability of IL-3 to induce strong liver-specific metabolic activity in bone marrow-derived liver progenitors may render these cells more suitable for use in future cellbased therapies.

\section{REFERENCES}

1. Sell S. Is there a liver stem cell? Cancer Res 1990;50:38113815.

2. Alison MR, Poulsom R, Jeffery R, et al. Hepatocytes from non-hepatic adult stem cells. Nature 2000;406:257.

3. Petersen BE, Bowen WC, Patrene KD, et al. Bone marrow as a potential source of hepatic oval cells. Science 1999;284: 1168-1170.

4. Krause DS, Theise ND, Collector MI, et al. Multi-organ, multi-lineage engraftment by a single bone marrow-derived stem cell. Cell 2001;105:369-377.
5. Fujii H, Hirose T, Oe S, et al. Contribution of bone marrow cells to liver regeneration after partial hepatectomy in mice. J Hepatol 2002;36:653-659.

6. Theise ND. Liver stem cells: The fall and rise of tissue biology. Hepatology 2003;38:804-806.

7. Avital I, Inderbitzin D, Aoki T, et al. Isolation, characterization, and transplantation of bone marrow-derived hepatocyte stem cells. Biochem Biophys Res Commun 2001;288:156-164.

8. Avital I, Feraresso C, Aoki T, et al. Bone marrow-derived liver stem cell and mature hepatocyte engraftment in livers undergoing rejection. Surgery 2002;132:384-390.

9. Alison MR. Liver regeneration with reference to stem cells. Semin Cell Dev Biol 2002;13:385-387.

10. Schrader JW. Interleukin-3. 4th ed. London: Elsevier Science Ltd, 2003.

11. McKinstry WJ, Li CL, Rasko JE, Nicola NA, Johnson GR, Metcalf D. Cytokine receptor expression on hematopoietic stem and progenitor cells. Blood 1997;89:65-71.

12. Evans CA, Ariffin S, Pierce A, Whetton AD. Identification of primary structural features that define the differential actions of IL-3 and GM-CSF receptors. Blood 2002;100: 3164-3174.

13. Testa U, Riccioni R, Diverio D, Rossini A, Lo Coco F, Peschle C. Interleukin-3 receptor in acute leukemia. Leukemia 2004;18:219-226.

14. Oh SH, Miyazaki M, Kouchi H, et al. Hepatocyte growth factor induces differentiation of adult rat bone marrow cells into a hepatocyte lineage in vitro. Biochem Biophys Res Commun 2000;279:500-504.

15. Schwartz RE, Reyes M, Koodie L, et al. Multipotent adult progenitor cells from bone marrow differentiate into functional hepatocyte-like cells. J Clin Invest 2002;109:12911302 .

16. Okumoto K, Saito T, Hattori E, et al. Differentiation of bone marrow cells into cells that express liver-specific genes in vitro: Implication of the Notch signals in differentiation. Biochem Biophys Res Commun 2003;304:691-695.

17. Yamazaki S, Miki K, Hasegawa K, Sata M, Takayama T, Makuuchi M. Sera from liver failure patients and a demethylating agent stimulate transdifferentiation of murine bone marrow cells into hepatocytes in coculture with nonparenchymal liver cells. J Hepatol 2003;39:17-23.

18. Miyazaki M, Akiyama I, Sakaguchi M, et al. Improved conditions to induce hepatocytes from rat bone marrow cells in culture. Biochem Biophys Res Commun 2002;298:24-30.

19. Fiegel HC, Lioznov MV, Cortes-Dericks L, et al. Liver-specific gene expression in cultured human hematopoietic stem cells. Stem Cells 2003;21:98-104.

20. Mitaka T, Kojima T, Mizuguchi T, Mochizuki Y. Subculture of proliferating adult rat hepatocytes in medium supplemented with nicotinamide and EGF. In Vitro Cell Dev Biol Anim 1996;32:469-477.

21. Berry MN, Friend DS. High-yield preparation of isolated rat liver parenchymal cells: A biochemical and fine structural study. J Cell Biol 1969;43:506-520.

22. Bas A, Forsberg G, Hammarstrom S, Hammarstrom ML. Utility of the housekeeping genes $18 \mathrm{~S}$ rRNA, beta-actin and glyceraldehyde-3-phosphate-dehydrogenase for normalization in real-time quantitative reverse transcriptase-polymerase chain reaction analysis of gene expression in human $\mathrm{T}$ lymphocytes. Scand J Immunol 2004;59:566-573.

23. Wang X, Willenbring H, Akkari $\mathrm{Y}$, et al. Cell fusion is the principal source of bone-marrow-derived hepatocytes. Nature 2003;422:897-901.

24. Alison MR, Poulsom R, Otto WR, et al. Recipes for adult stem cell plasticity: Fusion cuisine or readymade? J Clin Pathol 2004;57:113-120. 